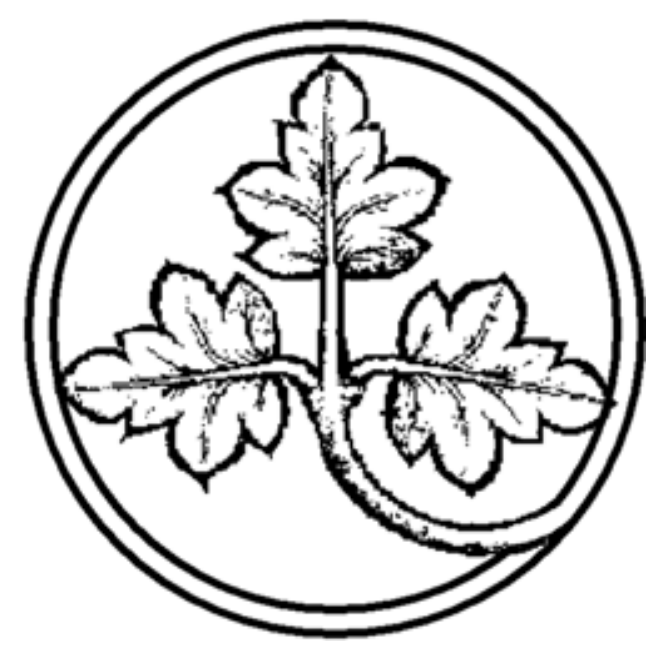

\author{
Preprints of the \\ Max Planck Institute \\ for Research on Collective Goods \\ Bonn \\ 2005/1
}

Cost and Benefits from Infrastructure Competition. Estimating Welfare Effects from Broadband Access

Competition

Felix Höffler 


\title{
Cost and Benefits from Infrastructure Competition. Estimating Welfare Effects from Broadband Access Competition
}

\author{
Felix Höffler* \\ June 13th, 2005.
}

\begin{abstract}
Competition between parallel infrastructures incorporates opposing welfare effects. The gain from reduced deadweight loss might be outweighed by the inefficient duplication of an existing infrastructure. Using data from broadband internet access for Western Europe 2000-2004, this paper investigates which effect prevails empirically. Infrastructure competition between DSL and cable TV had a significant and positive impact on the broadband penetration. Comparing the additional social surplus attributable to cable competition with the cable investments, we conclude that infrastructure competition has probably not been welfare enhancing.

Keywords: Infrastructure Competition, Service Competition, Broadband, Internet, Cable TV, DSL.
\end{abstract}

JEL-Classification: L51, L86, L96, L12, K23.

\footnotetext{
* Max Planck Institute for Research on Collective Goods. Kurt-Schumacher-Str. 10, 53113 Bonn, Germany. ++49(0)228 9141646. hoeffler@coll.mpg.de. I would like to thank Felix Bierbrauer, Christoph Engel, Martin Hellwig, Anke Hoeffler and Isabel Schnabel for helpful comments. All remaining shortcomings are mine.
} 


\section{Introduction}

Infrastructure versus service competition: this is one of the key issues in infrastructure industries. Regulators face the question whether to promote competition on the basis of a single infrastructure with regulated infrastructure access (service competition) or to promote the build-up of competing, parallel infrastructures. Although there is a trade-off between these two objectives, most telecommunications regulators try to provide a framework enabling both forms of competition. The UK regulator OFTEL stated: "By achieving the right level of regulation ..., both network and service competition can develop" (Oftel (2003)).

Furthermore, network competition itself incorporates opposing welfare effects. The gain from reduced deadweight loss due to higher competition might be outweighed by the inefficient duplication of an existing infrastructure. This is theoretically well understood (see e.g. (Laffont and Tirole, 2000, 127-128) for the case of telecommunications, or Mankiw and Whinston (1986) for the general case of inefficient market entry). What is far less clear is which effect prevails empirically. In order to contribute to closing this gap, in this paper we offer an empirical investigation into the increase in the use of broadband Internet access. We find that infrastructure competition had a significant and positive effect on the broadband penetration. In Western Europe ${ }^{1}$ - ceteris paribus - penetration would have been ca. $20 \%$ lower without competition from broadband cable. Using pricing data from the retail market, we approximate the maximum additional social surplus from competition. Viewing this in light of the investment of cable companies into broadband, we conclude that cable competition has not been welfare enhancing.

Broadband access provides a good example of the general question of the pros \& cons of infrastructure competition. It is usually realized by DSL (digital subscriber line) or cable modem. DSL uses the PSTN (public switched telephone network), cable modem uses the cable TV infrastructure. A significant sunk investment for upgrading the network is required in both cases. However, while PSTN covers all households, only a fraction are passed by (i.e. can be hooked up with) cable TV, thus the extent to which infrastructure competition is possible is limited.

A brief comparison of the US and Western Europe suggests a basic intuition about the resulting effects of competition. The percentage of homes passed by cable TV is far higher in the US. Therefore, competition is more intense, and cable has a higher market share in the broadband market. This can lead to higher broadband penetration levels (see Figure 1).

We first shortly reflect some theoretical considerations concerning this intuition and then use the heterogeneity within Western Europe with respect to cable competition to focus on the empirical question. We refer to two alternative theoretical predictions. A simple model of competition for a homogenous

\footnotetext{
${ }^{1}$ Western Europe, in the following, comprises the European Union, excluding Greece but including Norway and Switzerland. There are virtually no broadband subscribers in Greece; according to the EU-Commission only 10.000 in January 2004, see EU Commission (2004b).
} 


\section{Western Europe vs. US}

Year End 2003

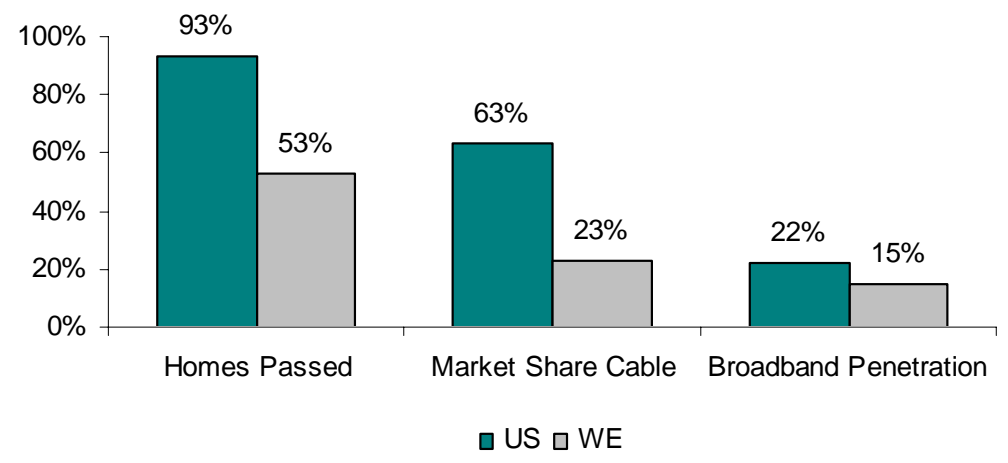

Figure 1: Cable competition in the US and Western Europe

product just predicts that the more dominant a firm is the higher prices will be and therefore penetration will be low. Alternatively, one could think of a spatial model with entry cost for each additional region. Competition could reduce rents in the market game so heavily that firms will enter only a small fraction of all markets, and penetration might eventually be even lower due to competition.

We confront this theoretical discussion with empirical evidence from Western Europe for the period 2000-2004. We consider a list of additional explanatory variables (GDP, population density and other) and run a pooled regression on the data panel. We find that cable competition has an inverted u-shaped effect on the penetration with broadband access, with a peak for a cable market share of about $50 \%$. We use the - highly significant - coefficients to estimate the extent to which penetration would have been lower in the absence of cable competition and we evaluate the lower quantity at historic broadband prices. Finally, the estimate for the additional social surplus from cable competition is compared to estimates for the upgrade investments. Though no definite evaluation of the overall welfare effect can be given (as we can give only ranges for the estimates of relevant cable investment with respect to common cost problems and the uncertain lifetime of the equipment), it seems most likely that the welfare effect was, at most, neutral, if not negative.

There is an extensive literature on the market for broadband internet access. An overview is provided in Crandall (2003). Theoretical papers have discussed the interaction between infrastructure and service competition: Bourreau and Dogan (2005) investigate the incentives for an incumbent and an entrant a regulator sets by imposing obligations to unbundle the local loop. They allow for 
flexibility about the timing of entry and the entrants decision to use the unbundled local loop or to build up their own, potentially higher quality, infrastructure. Their theoretical model highlights that an unregulated incumbent can have an incentive to delay the adoption of an alternative (i.e. cable) infrastructure. This can be welfare decreasing if the alternative is quality improving. Similar ideas are formulated in Bourreau and Dogan (2004). Foros (2004) offers a theoretical analysis of service competition in the broadband market. Foros and Kind (2003) discuss the welfare effects of (mandated) uniform prices and find that uniform prices will decrease regional coverage. The important question to which extend regulation and competition, by lowering monopoly rents, affects the geographical coverage has been addressed in Faulhaber and Hogendorn (2000).

While the theoretical prediction for the impact of network competition on the penetration are ambiguous, the empirical result of a positive impact are largely undisputed. In line with our findings Aron and Burnstein (2003) (for the US) and Distaso, Lupi, and Manenti (2004) (for the European Union) both find a significant positive correlation between network competition and broadband penetration. We contribute to these papers by using a different functional form (quadratic) and by employing different additional explanatory variables. More importantly, we try to take the analysis one step further by actually calculating the overall welfare effect of network competition by comparing additional consumer surplus to the cost of network upgrade.

Similar attempts to calculate the welfare effects of competition (at least for estimating the additional consumer surplus) can be found in Goolsbee and Petrin (2004). They try to estimate the consumer surplus attributable to the competition in the TV market between satellite and cable. Other papers try to estimate the welfare effects of new products and their regulations (Petrin (2002), Hausman (1997)). All these papers have available detailed pricing data such that they are able to estimate demand functions as a basis for their welfare analysis. Such data are not available for the European broadband market. Therefore, we cannot use estimations for demand functions but have to restrict our analysis to an estimate of the upper bound of the additional consumer surplus.

Broadband access is also of high political relevance. In their "eEurope 2005" program the European Union is highly committed to increasing broadband penetration, see EU Commission (2002) and EU Council (2002). Apart from whether this goal makes sense per se, there is a question of the best means for achieving this goal. With the recent introduction of regulated wholesale obligations for DSL, it is clear that the EU actively supports service competition (EU Commission (2003b)). Although not the focus of this paper, the empirical results can also contribute to this discussion. The data suggest that service competition has been less effective than network competition so far. Countries with more intense service competition do not exhibit significantly higher penetration rates.

The remainder of the paper is organized as follows. Section 2 explains the broadband industry in more detail. Section 3 discusses some policy issues of the sector. Section 4 reflects some theoretical ideas. Section 5 is empirical, presenting the data, the model to be estimated, and a discussion of the estimation 
results. Section 6 concludes by discussing the policy implications.

\section{Broadband Industry}

Technology Broadband describes a form of Internet access with a relatively high transmission rate. At a minimum, broadband must exceed the standard ISDN data transmission rate of $128 \mathrm{kbit} / \mathrm{s}$. We will focus - similarly to the OECD ((OECD, 2004a, p.6)) - on products with more than $250 \mathrm{kbit} / \mathrm{s}$. Since most of the mass market products do not exceed 1,000 kbit/s (1 mbit/s), in the following, broadband means roughly transmission rates between 0.5 and $1 \mathrm{mbit} / \mathrm{s}$.

The two main access technologies in Europe and in the US are DSL and cable modem. In both cases the necessary upgrades of the underlying infrastructure exhibit strong economies of scale. Upgrades take place "region by region". It is prohibitively costly to supply only a single household with broadband access. If the network in a region has been upgraded, the cost of providing broadband access to a particular household connected to the network is virtually zero. Although guaranteeing a certain transmission rate requires a backbone capacity (i.e. capacity of the jointly used part of the network) which is increasing in usage, the main cost drivers (see below) are not related to the usage. Having two parallel infrastructures covering the same households, thus constitutes an (inefficient) duplication of assets.

In more detail, DSL is based on the PSTN network, and the upgrades required for broadband are the following: At the customer's premises a splitter (to split the data traffic from the voice traffic) and a DSL modem are needed, and several upgrades in the public network (in particular to reinforce signals depending on the distance to the next local exchange) have to take place. The key cost driver is the maximum distance of a household to the nearest exchange with DSL equipment (which is about 5 Kilometers, but depends also on the quality of the telephone line, see e.g. http://www.everythingdsl.com).

Alternatively, the infrastructure of cable TV can be used. Because the cable TV infrastructure was built originally for broadcasting only, it is in a "tree" structure and only "one-way". Upgrading requires cable modems at the customer premise as well as (i) the digitalization of the network (ii) the introduction of a back-channel, which is the main cost driver (iii) the reduction of the homes per segment to ensure bandwidth, and (iv) backbone upgrades (see e.g. Ovum (2003)). There are also other technological solutions, which might play a role in the future, but which have not been of significance for the period under investigation. These are satellite and wireless broadband access (fixed-wireless access, WiFi, WiMax, UMTS). ${ }^{2}$ By the beginning of 2004, these technologies accounted for less than $5 \%$ of all broadband access in the European Union (EU

\footnotetext{
${ }^{2}$ At the end of 2004, all these technologies are still immature. WiFi is a shared bandwith medium and suffers from the fact that the bandwith decreases with each customer logged into the same hot spot, thus bandwith is hard to guarantee. WiMAX is still immature in technological terms. UMTS does typically not offer download capacities in excess of $500 \mathrm{kbps}$, and like WiFi availability decreases with the number of user in the same radio cell.
} 
Commission, 2004, p.55).

Regulation While the cable industry is not subject to access regulation, all countries in the sample are subject to some form of third party access regulation for the DSL market. Competitors in the DSL market can realize broadband access for customers by four different means: Unbundled local loop (ULL), line sharing (shared access), bitstream access (a certain technologically defined use of the incumbents assets), and pure reselling of the telecommunications incumbent's network. Prices for these different usages of the telecommunications incumbent's network are all $^{3}$ regulated. Thus, the market structure within the DSL-segment is mainly a result of regulatory decisions. The investment intensity for the competitor declines from ULL (where the competitor has to bear nearly the full cost of network upgrading) to reselling (where the competitor has no infrastructure investment cost at all). In January 2005 in the EU competitors' DSL lines were realized to $16 \%$ on ULL, $21 \%$ on shared access, $35 \%$ bitstream access, and $28 \%$ resale ((EU Commission, 2005, p.33)).

Market Structure In all countries the incumbent telecommunications operator offers DSL and has a dominant retail market position in the DSL segment. Some markets (UK, Netherlands, France) exhibit a significant wholesale DSL market. This has resulted in lower (40-50\%) market shares for the incumbents in the DSL retail market. In some countries the telecommunications incumbent used to own the cable infrastructure (Germany, Sweden, in both countries the incumbent sold its cable TV business in 2003). In Portugal and Norway the incumbent's cable TV subsidiary still holds a dominant position in the cable TV market (market share $>80 \%$ in 1Q2004).

Financial Crisis Nearly all cable companies went through a phase of financial stress in 2002/2003. All companies had invested heavily in the 2000 Internet bubble following a "build and they will come" approach. With financial markets becoming reluctant to support high risk investments, the largest two European cable operators (NTL and UPC), accounting for almost half of all subscribers in Western Europe, had to file for bankruptcy in 2002. Other large operators like Telewest (UK) or ONO (Spain) went through considerable financial restructuring, involving significant debt-for-equity swaps and equity injections by shareholders. Reemerging after Chapter 11 bankruptcy proceedings or financial restructuring, investments were reduced significantly in 2003 and (revenue) growth strategies have been replaced by a focus on short-term cash generation.

\section{Policy Issues}

There is a widespread common understanding in the political arena that broadband Internet access should be politically supported. In its program "eEurope 2005" the EU Commission stated an ambitious goal: by 2005 half of all Inter-

\footnotetext{
${ }^{3}$ An exception being resale, where in some countries like Germany the incumbent had no reselling obligation but nevertheless used reseller as an additional sales channel. However, this sort of reselling accounts only for a minor part of the DSL market.
} 
net access lines should be broadband. ${ }^{4}$ The EU initiated the development of broadband strategies to achieve this goal in all member countries. Germany's objective, for instance, is to reach more than 20 million broadband subscribers by 2010 (BMWA (2003)) - almost four times the number at the end of 2004 .

Views differ significantly about how these targets can be met. The OECD clearly favors competition over subsidization (OECD (2004b)), without specifying whether this means infrastructure or service competition. The EU Commission provides scope for subsidies and for promotion of competition. Most member countries' initiatives focus on subsidization of either demand (e.g. Austria with tax-deductible broadband expenditures (EU Commission, 2004, p.29)), or supply (Italy plans to support the incumbent operator by upgrading its network with up to $€ 270$ million, see Börsenzeitung (2004)).

The EU has also tried to increase service competition mainly with unbundled local loop access. This has been of limited success, see EU Commission (2004b). Thus, new initiatives try to reinforce service competition, based on wholesale models requiring lower investments from competitors, compared to solutions realized via unbundled local loop. The EU has identified wholesale DSL as a market which should be ex ante regulated (EU Commission (2003a)). Bit stream access has been further specified by the European Regulators Group as a regulated wholesale product, see ERG (European Regulators Group). No overall strategy, however, yet exists, which has quantified and compared the effects from infrastructure competition, service competition and subsidization.

\section{Theoretical predictions}

The theoretical predictions to be tested are very simple and well known in the literature. The most simple setup would treat the market for broadband access as a homogenous good market which could be served by either one or two firms. If it is served by one firm this firm would realize the monopoly solution: prices are high and quantities are low, i.e. we expect a low penetration with broadband access. Competition would drive prices down and the more intense competition is, the higher the penetration would be. Thus, there is a non-monotonic relationship between the broadband penetration and the market share of the second firm (i.e. the cable technology), taking local minima at 0 and 1 . The most simple assumption would be a single peaked, inverted $\mathrm{u}$-shaped relationship. This is also suggested by Figure 2 which provides a cross-country comparison of the market share of the cable industry (in terms of subscribers) versus the national household penetration with broadband access lines. Thus, the prediction of this simple "competition model" would be that more intense competition raises the broadband penetration.

\footnotetext{
${ }^{4}$ Reaffirmed by EU Council (2002). However, already by the end of 2002 and in the light of the financial crisis of the industry, Errki Liikanen, the responsible EU-Commissioner in charge, stated: " The EU recognises the importance of exploiting the broadband potential, although the financial problems of the sector are making the 2005 objectives more difficult to achieve" (Liikanen (2002)).
} 
Cable Market Share vs. Penetration

Western Europe 1Q2004

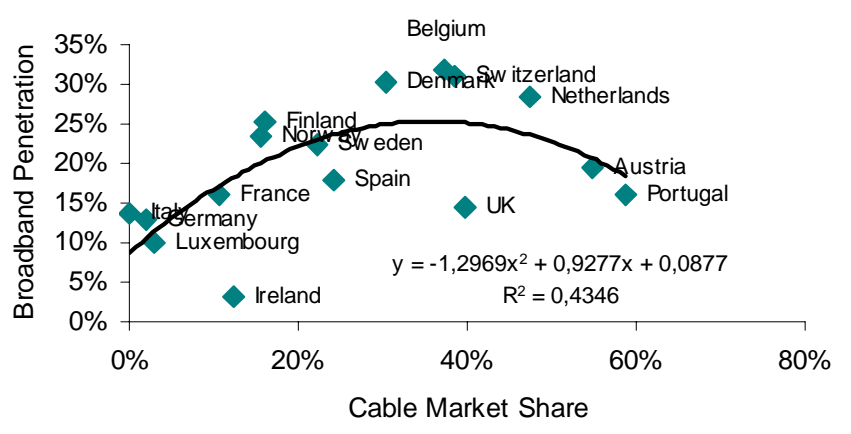

Figure 2: An inverted u-shaped relationship?

An alternative theoretical model focuses more on the spatial characteristic of the industry, taking into account that each firm has sunk cost to upgrade the infrastructure region by region. Starting from the same assumption that infrastructure competition reduces prices, one could argue that lower prices reduce the incentive to cover additional regions. With strong competition price will be lower and penetration higher for those markets covered by the two firms, but less regions will be covered. Such spatial models have been developed by e.g. Foros and Kind (2003) and Höffler (2005). The overall effect of competition in this "spatial model" is ambiguous and could even be negative if competition is very strong and / or the sunk cost of upgrading are high.

If the "competition model" is correct the question arises if the additional consumer surplus overcompensates the negative welfare effects on the supply side, in particular whether it covers the cost of network duplication. The standard theory of market entry into markets for homogenous products predicts that this is not the case, i.e. that inefficient market entry happens (Mankiw and Whinston (1986)). This is true, however, only up to an integer problem: the smaller the number of possible entrants the more likely that inefficiently low entry might occur (Perry, 1984, Table I, p. 320). Since in our case the question is whether one or two firms enter the market, the integer problem is most severe and the standard model predicts that inefficiently low as well as inefficiently high entry may happen. 


\section{Empirical Analysis}

We want to analyze and eventually reject the hypothesis that infrastructure competition from cable TV has increased social welfare as measured by the sum of consumer and producer surplus. In order to do so we estimate an upper bound for the amount of which broadband penetration would have been lower without competition from cable companies. This is done by a regression analysis using penetration and market share data, as well as data on other variables in order to control for additional causes for broadband penetration. We then evaluate the resulting quantity by a relatively high market price in order to get an upper bound for the consumer surplus attributable to cable competition. This is finally compared to an approximation of the cable upgrading cost based on accounting data for most of the relevant cable operators.

\subsection{Explaining Broadband Penetration}

\subsubsection{Data and Model}

We use data for 16 Western European countries on key explanatory variables for broadband penetration, most of which was provided by the research company, Baskerville, in August 2004. The Appendix provides a more detailed discussion of the data and the sources. We use quarterly data from 4Q2000 until 1Q2004, implying 224 observations. This data set virtually covers the whole industry history, since broadband as a mass market just started in 2000 , and there were less than 2 million broadband subscribers in Western Europe at the end of 2000 (implying a household penetration of $1.3 \%$ ), compared to 27 million subscribers in 1 Q2004 (16.7\% penetration).

Although broadband use has been increasing in all countries, growth patterns are significantly different with respect to the two underlying technologies. ${ }^{5}$ These different dynamics provide valuable heterogeneity across countries and time. Using the panel data set, we conduct a pooled estimation of the following equation:

$$
\begin{aligned}
\text { pen }_{i t}= & \beta_{0}+\beta_{1} \text { cable }_{i t}+\beta_{2} \text { cable }_{i t}^{2}+\beta_{3} \text { inctv }_{i t}+\beta_{4} \text { retail }_{i t} \\
& +\beta_{5} i s d n+\beta_{6} \ln g d p_{i t}+\beta_{7} \text { density }_{i t} \\
& +\beta_{8} t_{1}+\ldots+\beta_{20} t_{13}+\varepsilon_{i t}
\end{aligned}
$$

where for each period $t$ and country $i$ :

${ }^{5}$ At least six patterns can be distinguished: (i) Same quantities of cable and DSL (UK), (ii) Cable still ahead (Portugal, NL), (iii) DSL slowly overtaking (Belgium, CH), (iv) DSL with higher growth rates from the beginning (Denmark, Norway, France, Ireland, Sweden, Spain, Finland), (v) DSL dominant throughout (Germany, Italy, Luxembourg) (vi) Parallel development with DSL ahead (Austria). 


\begin{tabular}{ll} 
Name & Definition \\
\hline \hline PEN & broadband subscribers / all households \\
\hline CABLE & cable broadband subscribers / all broadband subscribers \\
INCTV & incumbent cable TV subscribers / all cable TV subscribers \\
RETAIL & incumbent DSL subscribers / all DSL subscribers \\
ISDN & ISDN subscribers / all households \\
LNGDP & $\ln (\mathrm{gdp} /$ capita), using PPP and annual averages \\
DENSITY & inhabitants / square kilometer \\
\hline $\mathrm{t}_{k}$ & time dummy \\
\hline \multicolumn{2}{c}{ CABLE We take the market share of the cable companies as a proxy for in }
\end{tabular}

frastructure competition. To cover the theoretical prediction of a non-monotonic relation we specified the relation to the broadband penetration with an additional quadratic term.

The additional variables are meant to cover the major other influences on the penetration.

RETAIL Penetration increasing competitive effects might not only stem from infrastructure competition but also from service competition. Since the terms for access to the incumbent's network are regulated, the incumbent's market share in the retail market for DSL can be regarded as mainly exogenous. Strong obligations by the regulator will yield a low market share in the DSL market and therefore more competition.

ISDN Supplying customers with more than one channel (typically three) via one access line, ISDN serves to some degree as a substitute for DSL. Though allowing only for narrowband Internet access (although with $128 \mathrm{kbit} / \mathrm{s}$ the difference to DSL has been not too large at least in the early years), it provides customers with one key feature similar to DSL, namely the ability to make and receive phone calls while connected to the Internet.

INCTV In some countries the telecommunications incumbent owns or owned large cable assets. Having both kinds of infrastructure in one hand probably has an influence on the degree of infrastructure competition and its effect on the broadband penetration. The telecommunications incumbent's market share in the cable TV market serves as a proxy for this influence.

LNGDP GDP per capita shall capture general differences in macroeconomic performance as well as differences in disposable income.

DENSITY Higher population density makes coverage with broadband services less costly.

Finally, we use period dummies since cable penetration as well as many explanatory variables exhibit a strong positive trend.

Clearly, there is country specific heterogeneity in the data which is not covered directly in the pooled estimation employing time dummies. However, the variables INCTV and DENSITY capture significant country specific heterogeneity since they vary strongly between countries but have virtually no variance over time. ${ }^{6}$

${ }^{6}$ This is also the reason why fixed effects estimations are not helpful in this case. 


\subsubsection{Estimation Results}

Table 1 shows the results for the pooled OLS estimation with robust standard errors.

\begin{tabular}{|l|c|c|c|c|c|c|}
\hline pen & Coef. & $\begin{array}{c}\text { Robust Std. } \\
\text { Err. }\end{array}$ & $\mathrm{t}$ & \multicolumn{2}{|c|}{ P>t } & \multicolumn{2}{|c|}{ [95\% Conf. Interval] } \\
\hline cable & .2413668 & .0309319 & 7.80 & 0.000 & .1803778 & .3023558 \\
\hline cable2 & -.234785 & .0310731 & -7.56 & 0.000 & -.2960524 & -.1735177 \\
\hline inctv & .0551709 & .0100692 & 5.48 & 0.000 & .0353174 & .0750245 \\
\hline retail & .0337216 & .0241694 & 1.40 & 0.164 & -.0139336 & .0813768 \\
\hline isdn & -.1013194 & .0254529 & -3.98 & 0.000 & -.1515053 & -.0511336 \\
\hline lngdp & .0483591 & .017614 & 2.75 & 0.007 & .0136293 & .0830889 \\
\hline density & .0001489 & .0000218 & 6.83 & 0.000 & .0001059 & .0001919 \\
\hline cons & -.371725 & .1689235 & -2.20 & 0.029 & -.7047946 & -.0386554 \\
\hline
\end{tabular}

Table 1: Regression Results

The $R^{2}$ of the pooled estimation equals 0.72 with $($ prob $>F)<.0001$, and the time dummies are jointly significant, exhibiting a strong positive trend. ${ }^{7}$ The results strongly support the assumed inverted u-relationship between cable market share and the broadband penetration. Furthermore, we find a peak almost perfectly at a $50 \%$ market share of the cable technology. We interpret this as evidence that actual infrastructure competition can explain broadband penetration in the sense of the "competition model", and that the effect is strongest where competition is most intense, i.e. at equal market shares. Thus, we reject at least the strong formulation of the "spatial model" which predicts a negative relationship between competition and penetration due to lower rents and therefore lower regional coverage.

The incumbent's market share in the cable TV market is significant but has an unexpected sign. The more cable TV assets a telecommunications incumbent controls the higher the broadband penetration will be. One explanation in the spirit of the "spatial model" could be that if the telecommunications incumbent controls also the competing technology he need not be afraid of future infrastructure competition. The incumbent rolls out a larger network (i.e. upgrades more regions for DSL), anticipating that he will remain a monopolist there. However, the result is to be interpreted with care. It is driven strongly by two countries in the sample, Portugal and Norway. In both countries, the incumbent is the dominant player in the cable TV market, and cable was the dominant technology for providing broadband access, at least in the beginning of the period considered here. For Germany and Sweden, the market share of the incumbent dropped from "dominant" to "zero" in the first quarter of 2003 due to the divestment of the cable assets by Deutsche Telekom and Telia, respectively. One cannot expect an immediate impact from this on the infrastructure

\footnotetext{
${ }^{7}$ The qualitative results, however, are affected only to a limited extend by the dynamics. See the Appendix for an isolated investigation of the last period and for results on a cross country analysis for a larger sample of countries.
} 
competition for the remaining periods. Nevertheless, the data clearly reject the opposite hypothesis that ownership in cable TV assets has a significantly negative effect on the broadband penetration

Service competition, as measured by RETAIL, the market share of the telecommunications incumbent in the DSL market, shows the expected sign but is not significant. Thus, more intense competition in the retail market for DSL does not seem to significantly increase the broadband penetration. This sheds some doubt on the effectiveness of service competition.

The effect of ISDN is significant: As a partial substitute for DSL it negatively influences the broadband penetration. Also the GDP per capita is significant and shows the expected sign. Higher income has a positive effect on the broadband penetration. Finally, the results confirm that densely populated countries exhibit higher broadband penetration, because providing broadband is less costly there.

We performed various alternative regressions (documented in the Appendix) to check for the robustness of the results. The pooled OLS could suffer from an endogeneity problem. An instrumental variable regression, using the lagged value of the market share of cable and the cable companies' market share in the TV market as instruments for the market share of cable, produces very similar and significant values for the coefficients as the pooled OLS. Broadband is a new market with strong growth rates. To check for the robustness with respect to the dynamics we conducted various cross country regressions, also with an enlarged country panel, which qualitatively support the hypothesis of an inverted urelationship between penetration and cable market share. Finally, we included various additional variables which are frequently used in similar regressions (like PC penetration, or the cable homes passed) but found no additional explanatory value.

\subsection{Consumer Surplus}

We are looking for an upper bound for the additional consumer surplus due to cable competition. The last period in our sample, 1Q2004, is taken as our point of reference. We deduce, country by country, in a ceteris paribus approach, how many fewer broadband subscribers there would have been in 1Q2004, if no cable competition had existed (i.e. we set cable $_{i t}=0 \forall i$ in an ex-post estimation for 1Q2004 and deduct the original values). Without cable competition the number of broadband subscribers would haven been approximately $17 \%$ lower (22.4 instead of 26.8 million subscriber in 1Q2004). On average this translates into a delta of $2.7 \%$ points of penetration. In countries with very strong cable competition this delta goes up to almost $6 \%$ points (e.g. Netherlands with $22.6 \%$ instead of $28.4 \%$, or Austria with $13.6 \%$ instead of $19.4 \%$ ).

Since due to the lack of consistent pricing data on a quarterly basis it is not possible to estimate demand functions, we have to make an approximation when evaluating the consumer surplus. Inframarginal consumers have a higher willingness to pay, thus taking prices at the end of the first quarter of 2004 would underestimate consumer surplus. Fortunately, consistent pricing data are 
available for October 2003, a date where the number of broadband customers was between 3.3 and 6.4 million lower than at the time we are interested in (end of 1Q2004). This corresponds well to the 4.4 million difference in subscribers we estimate are due to the cable competition. Assuming penetration pricing (i.e. falling prices over time) the prices of October 2003 are a good approximation for the upper bound of the inframarginal consumers willingness to pay. The appendix contains the details for the prices used for each country. In total, for all 16 Western European countries, the approximation yields a maximum additional consumer surplus attributable to cable competition of $€ 2.8$ bn. per annum.

\subsection{Producer Surplus}

The producer surplus is reduced by competition by two effects. First, lower operative profits due to more competition; second, the expenditures of the cable companies and their network upgrade investments. ${ }^{8}$ We cannot estimate the first part and therefore neglect it, which again (by understating the reduction of producer surplus) biases the resulting welfare analysis in the direction of overestimating the benefits from infrastructure competition.

For the upgrading cost, we analyzed the financial statements of the cable operators active in the broadband markets of the 16 countries. Accounting figures are available for most of them (again, the Appendix gives the details). Their capital expenditure for the years 2000-2003 amount to at least $€ 20.5$ billion. Restriction to this period probably underestimates the cost of cable competition, since significant investment might well have taken place before that period.

Cable companies did not only invest in upgrading the network for broadband access. There are also maintenance investments, investments in expanding the coverage, and investments in the digitalization of the network. The latter is a common cost for two distinct services, digital TV and broadband access. As a rule of thumb, a split of $10 \%$ maintenance, $15 \%$ expansion, $15 \%$ digital $\mathrm{TV}$, and $60 \%$ broadband seems reasonable, but real rates differ widely among companies. The lifetime of the assets is also difficult to estimate. Some assets are extremely long-lived (like the physical infrastructure), other like network intelligence are more short-lived. Because the largest investments took place in 2000 (34\% of the whole period 2000-2003), as of 2004 these assets are already at least 3 years old. An average remaining asset lifetime of five years in 2004 might be a good approximation.

\footnotetext{
${ }^{8}$ It could, in principle, be increased by the profits of the entrant. As already mentioned, for the period investigated here, the cable industry rather made losses than profits and the two largest operators, accounting for almost half of the subscribers, filed for bancuptcy.
} 


\subsection{Welfare Effect}

Formally, we want to approximate the (annual) welfare impact $W$, equal to consumer surplus plus producer surplus, minus the attributed capital expenditures.

$$
W=C S+P S-s \cdot C a p e x / L,
$$

where $L$ denotes the lifetime of the assets, and $s$ the fraction of total capex attributed to broadband access. Note that we do not discount the positive effects from penetration, although there is an obvious time lag between investment and full network usage.

\begin{tabular}{|c|c|c|c|c|c|c|c|c|c|c|c|}
\hline & 0 & $10 \%$ & $20 \%$ & $30 \%$ & $40 \%$ & $50 \%$ & $60 \%$ & $70 \%$ & $80 \%$ & $90 \%$ & $100 \%$ \\
\hline 1 & 2.846 & 832 & -1.183 & -3.197 & -5.211 & -7.225 & -9.240 & -11.254 & -13.268 & -15.282 & -17.297 \\
\hline 2 & 5.692 & 3.678 & 1.663 & -351 & -2.365 & -4.379 & -6.394 & -8.408 & -10.422 & -12.436 & -14.451 \\
\hline 3 & 8.538 & 6.524 & 4.509 & 2.495 & 481 & -1.533 & -3.548 & -5.562 & -7.576 & -9.590 & -11.605 \\
\hline 4 & 11.384 & 9.370 & 7.355 & 5.341 & 3.327 & 1.313 & -702 & -2.716 & -4.730 & -6.744 & -8.759 \\
\hline 5 & 14.230 & 12.216 & 10.201 & 8.187 & 6.173 & 4.159 & 2.144 & 130 & -1.884 & -3.898 & -5.913 \\
\hline 6 & 17.076 & 15.062 & 13.047 & 11.033 & 9.019 & 7.005 & 4.990 & 2.976 & 962 & -1.053 & -3.067 \\
\hline 7 & 19.922 & 17.908 & 15.893 & 13.879 & 11.865 & 9.851 & 7.836 & 5.822 & 3.808 & 1.793 & -221 \\
\hline 8 & 22.768 & 20.754 & 18.739 & 16.725 & 14.711 & 12.696 & 10.682 & 8.668 & 6.654 & 4.639 & 2.625 \\
\hline 9 & 25.614 & 23.600 & 21.585 & 19.571 & 17.557 & 15.542 & 13.528 & 11.514 & 9.500 & 7.485 & 5.471 \\
\hline 10 & 28.460 & 26.445 & 24.431 & 22.417 & 20.403 & 18.388 & 16.374 & 14.360 & 12.346 & 10.331 & 8.317 \\
\hline
\end{tabular}

Table 2: Upper Bound for Welfare Effects (bn.€)

Table 2 shows the results for (2). We cannot provide a point estimate, mainly due to the lack of a precise figure for the lifetime of the assets $L$ and the percentage of investments attributable to broadband, $s$. If the lifetime of the assets is short and nearly all of the investments are attributed to broadband, the welfare effect is clearly negative, and vice versa. We have indicated the parameter region considered most likely in the table $(4 \leq L \leq 6,50 \% \leq s \leq 70 \%)$. For this parameter region, the overall welfare effect is just about neutral. However, these number reflect only an upper bound for the welfare effect as we we considerably biased all estimates in favor of the positive welfare effects from competition. We have (i) not considered pre-2000 investment, (ii) used no discounting although investment predates usage (iii) not taken into account the business stealing effect (i.e. negative effects on producer surplus of DSL-providers), and (iv) used relatively high prices to estimate the marginal willingness to pay and abstracted from variable cost. Table 2 therefore suggests that the overall welfare effect has been negative.

\section{Discussion}

The analysis suggests that actual infrastructure competition from cable TV has had a significant positive effect on broadband penetration in Western Europe. As an order of magnitude, the estimation results indicate that, given a penetration rate of $16.7 \%$ in Western Europe at the beginning of 2004, on average $2.7 \%$ points can be attributed to cable competition, and a maximum of $6 \%$ points per national market. We find evidence for an inverted u-shaped relationship 
between the market shares of the two competing technologies DSL and cable and the broadband penetration. The more equal the market shares of different infrastructures are, the higher the broadband penetration will be. The results therefore support that any policy dedicated a priori to high penetration rates should enable infrastructure competition.

However, the welfare gains from the increase of penetration due to infrastructure competition seem not to be sufficiently large to overcompensate the very high investments into the basically redundant alternative cable infrastructure. The industry history up to 2004 suggests that, overall, the welfare effect - in the absence of any additional welfare enhancing effects from broadband access - of cable competition is likely to have been negative. The critical situation of almost all firms in the industry - high debt burdens, financial stress and restructuring, bankruptcy filings and painful reemergence from chapter 11 - already indicates that producer surplus had been negative. The estimates presented here suggest that the additional consumer surplus from competition could not compensate for that.

These results rest on various important assumptions. We have treated the market share of cable as an exogenous variable although an endogeneity problem might exist. However, attempts to control for this issue in an instrumental variable estimation confirm our empirical results. Furthermore, the telecommunications incumbent's market share is treated as an exogenous variable, where again one might argue that infrastructure competition has an effect on service competition (the DSL market). Since regulation is key to the DSL market we nevertheless treated the DSL market share as a variable exogenously determined by the regulator. Finally, we cannot look into the future, i.e. the welfare analysis assumes that no significant changes occur in the future. In particular, we implicitly assume that investment intensity for additional customers stays constant over time.

Thus, policy recommendations have to be formulated with care. The results presented here nevertheless underline that the drawback form duplication of infrastructure is not a purely theoretical case but can become a real threat. In the absence of positive externalities from broadband this casts some doubt on advocating that infrastructure competition will yield the most desirable industry outcome. Whether broadband exhibits strong externalities which could compensate the negative effects in terms of Marshallian social surplus is an open question. While Crandall (2003) argues for strong externalities of bandwagon effects from broadband along the lines of the literature on network externalities, ${ }^{9}$

\footnotetext{
${ }^{9}$ Crandall argues that critical mass or "chicken-egg" problems might prevent a socially beneficial network size and socially beneficial network choice. Customers will not sign up for broadband as long as attractive applications are lacking. No company will develop applications if there are few potential broadband users. Although this effect might exist, Liebowitz and Margolis claimed "network externalities [to be] an uncommon tragedy"(Liebowitz and Margolis (1994)). Typically, network effects can be internalized via the market, e.g. with vertical integration or alliances between network operators and content providers. This has not happened in the broadband industry which could be taken as an argument that there was no "critical mass" problem to be overcome and therefore no network externality. Virtually none of the large telecommunications operators has diversified significantly into the content
} 
Liebowitz and Margolis (2002) do not see any clear evidence for externalities.

While the analysis calls for caution with respect to infrastructure competition it at the same time finds no support for the hypothesis that service competition has had a significantly positive impact on broadband penetration. Similar results have been derived by Distaso, Lupi, and Manenti (2004).

To provide a broader analytical basis for the general discussion of network versus service competition, in particular in developing markets, it is important to gain a better understanding of the effects on investment incentives. An interesting field for further research would be to investigate whether network coverage is adversely affected by competition. Broadband Internet access on a more disaggregate level (i.e. to which extent regions within countries have been upgraded for the new service) could serve as a promising empirical test case. Furthermore, the interplay between service and infrastructure competition awaits more empirical analysis. To which extend does service competition limit the scope of network competition and is there any "optimal mix" of the two forms of competition a regulator should head for? Finally, the question whether demand and supply subsidies (being the most common policy instrument in the EU so far) are more effective than (network) competition awaits theoretical and empirical investigation.

\section{Appendix}

\subsection{Regression Data}

Most regression data were provided by the specialized broadband market intelligence company "Baskerville" in August 2004. We have cross-checked the data with the latest cross-country analysis of the EU (from May 2004 EU Commission (2004)) and deviations are very small (e.g. aggregate number of broadband subscribers deviates by less than $2 \%$ in both sources). Also, data from "Point Topic", an alternative research company, are quite similar to the data used in this analysis.

Most companies filings state the number of ISDN "channels" as "lines". Thus, we translate the ISDN channels reported by Baskerville on the basis of company information into subscriber figures, by taking 2 ISDN lines $=1$ ISDN subscriber, since on average ISDN provides 2 channels per physical access.

GDP data are from Eurostat, using annual averages. Since we want to interpret GDP/capita as a proxy for differences in the level of economic development rather than for short run deviations from the trend, we used annual averages.

Table 3 provides the summary statistics, Table 4 the correlation matrix of the data (excluding the time dummies).

industry and the merger between AOL (as an Internet service provider) and Time Warner (a content provider) was unsuccessful. 


\begin{tabular}{lccccc|}
\hline variable & Obs & Mean & Std. Dev & Min & Max \\
pen & 224 & .0908269 & .0764561 & 0 & .3173083 \\
cable & 224 & .3973484 & .2944095 & 0 & 1 \\
retail & 224 & .7752965 & .1526288 & .3681922 & 1 \\
isdn & 224 & .1568416 & .1327081 & .0114961 & .4857143 \\
gdp & 224 & 25189.29 & 5.668 .857 & 15300 & 45900 \\
inctv & 224 & .2036127 & .3090877 & 0 & .8854054 \\
density & 224 & 153.2116 & 120.3885 & 11.69321 & 478.0385 \\
\hline
\end{tabular}

Table 3: Summary Statistics

\begin{tabular}{lccccccc|}
\hline & pen & cable & retail & isdn & gdp & inctv & density \\
pen & 1 & & & & & & \\
cable & -0.1121 & 1 & & & & & \\
retail & -0.2751 & -0.0100 & 1 & & & & \\
isdn & -0.1526 & -0.2386 & 0.0563 & 1 & & & \\
gdp & -0.0334 & -0.3118 & 0.1149 & 0.5561 & 1 & & \\
inctv & 0.0028 & 0.0965 & 0.0466 & 0.1757 & -0.3186 & 1 & \\
density & 0.1766 & 0.1381 & -0.0942 & 0.0194 & 0.0884 & -0.3297 & 1 \\
\hline
\end{tabular}

Table 4: Correlation Matrix

\subsection{Prices}

The products (plans) represented in Table 5 have been selected to approximate the inframarginal consumers' willingness to pay in calculating the welfare gain from increased broadband penetration. They are selected as the incumbent's offer for a medium product quality (i.e. average transmission rate) compared to all other plans benchmarked by the OECD. Typically, the incumbent's prices are relatively high compared to other DSL and cable offerings. All plans include already significant connectivity on top of the pure access. Prices are therefore an upper bound for the value of the access. (e.g. free 10.000 MB imply already a de facto flat rate for most users with almost 14 hours/month continuous download with $0,5 \mathrm{MB} / \mathrm{s}$ ).

\begin{tabular}{|llllcc|}
\hline Country & Company & Plan & downstream1 upstream & price in $€$ connectivity included? \\
\hline Austria & TA & AonSpeed 500MB & 768 & 128 & 28,06 500MB \\
Belgium & Belgacom & ADSL Skynet Go & 3000 & 128 & 36,06 10.000MB \\
Denmark & TDC & CableModem & 1024 & 128 & 44,82 unlimited \\
Finland & TeliaSonera & ADSL & 1024 & 512 & 107,69 unlimited \\
France & FT & eXtense fidelite & 1024 & 128 & 67,92 unlimited \\
Germany & DT & T-Online dsl 1000 & 768 & 128 & $27,051.000 \mathrm{MB}$ \\
Ireland & eirecom & eircom i-stream starter (residential) & 512 & 128 & $45,914.000 \mathrm{MB}$ \\
Italy & TI & Alice 640 & 640 & 128 & 53,46 unlimited \\
Luxembourg & P\&T & SpeedSurf RUN & 512 & 128 & $71,6715.000 \mathrm{MB}$ \\
Netherlands & KPN & ADSL Komfort & 1024 & 160 & 46,87 unlimited \\
Norway & Telenor & Online ADSL oppgradert & 704 & 128 & 42,25 10.000MB \\
Portugal & SAPO (PT) & SAPO ADSL.PT & 512 & 128 & 44,47 20.000MB \\
Spain & Telefonica & Linea ADSL 512 & 512 & 128 & 95,03 unlimited \\
Sweden & Telia & Telia Broadband 500 & 500 & 400 & 33,28 unlimited \\
Switzerland & Swisscom & Broadway ADSL600 & 600 & 100 & 35,62 unlimited \\
UK & BT & BT Yahoo! Broadband Home & 512 & 256 & 38,71 unlimited \\
\hline Source: OECD, Benchmarking Broadband Prices in the OECD, 18.6.2004, DSTI/ICCP/TISP (2003)8/final \\
all prices as of October 2003 incling \\
prices originally in USD, PPP, including VAT, converted into $€$ using average Interbank exchange rate of October 2003
\end{tabular}

Table 5: Broadband Access Prices 


\subsection{Cable Capex}

Investment data have been collected for all cable companies whose broadband subscribers have been considered in the analysis of the broadband penetration. Sources are company reports, except for com hem (national filing with the Swedish Companies' House) and Cablecom (Deutsche Bank High Yield Research estimates). Wherever possible we used "capital expenditures" or "cash used for purchase of tangible assets" to exclude financial investments. Detailed investment data are available for approximately three quarter of the companies (representing $72 \%$ of all subscribers covered). We assume the same investment intensity for the remaining companies and the same investment structure for missing periods (i.e. high investments in 2000 , lower in consecutive years). Table 6 shows the details.

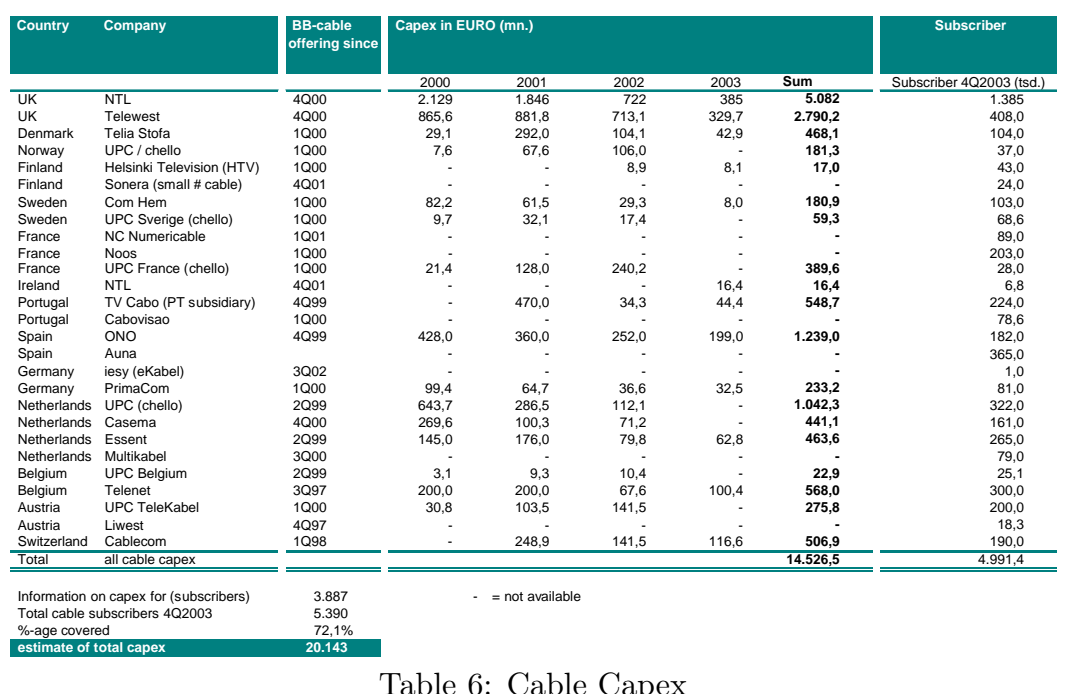

\subsection{Robustness}

\subsubsection{Panel Regressions}

Additional explanatory variables We performed the same pooled OLS with time tummies also with two additional variables, the homes passed by cable TV and the PC penetration. Table 7, column 3, shows the estimation results for the following estimation equation:

$$
\begin{aligned}
\text { pen }_{i t}= & \beta_{0}+\beta_{1} \text { cable }_{i t}+\beta_{2} \text { cable }_{i t}^{2}+\beta_{3} \text { inctv }_{i t}+\beta_{4} \text { retail }_{i t}+\beta_{5} \text { passed }_{i t} \\
& +\beta_{6} i s d n+\beta_{7} \ln g d p_{i t}+\beta_{8} \text { density }_{i t}+\beta_{9} p c_{i t} \\
& +\beta_{10} t_{1}+\ldots+\beta_{22} t_{13}+\varepsilon_{i t},
\end{aligned}
$$

where passed $=$ homes passed/all households and $p c=\mathrm{PCs} /$ population. Data are again provided by the market research firm, Baskerville. For some coun- 
tries, no information on the "homes passed" is available from Baskerville. Missing data have been added, using the research company advanced television Ltd. (http://www.advanced-television.com /PDF /homes_ passed_ projections.pdf). These data focus on digital cable homes passed and therefore underestimate the homes passed for the countries where this source has been used.

Both variables are not significant at the $10 \%$ level and the regression results remain widely unchanged compared to the model presented in the main body of the text (column 1 in Table 8). Since cable firms can compete with DSL-offers only for the homes passed, the homes passed and the market share of cable are positively correlated but as the regression results show, including the homes passed does not improve the estimation.

The PC penetration is a standard explanatory variable for Internet penetration (see e.g. Chinn and Fairlie (2004)). Not only narrowband applications, but also most broadband applications, require PCs. We nevertheless omitted the PC penetration as an explanatory variable. Table 7 shows that the PC penetration is not significant. This surprising result is only to a very limited extent due to the positive correlation between $p c$ and $\ln g d p$. These variables are not jointly significant at the $5 \%$ level $(\operatorname{Prob}>F=.0716)$. To understand this, it is important to distinguish between the Internet penetration (including narrowband) and the broadband penetration. Broadband subscribers are a subset of Internet subscribers. Internet subscribers might be limited by the PC penetration. But as long as not every Internet subscriber is broadband, the PC penetration will not limit the broadband penetration. Thus, it seems plausible that a PC penetration in excess of some critical value will not affect the increase in the use of broadband. Given a relatively homogeneous country sample (homogeneous with respect to the level of the countries development towards the "information society"), all countries seem to be beyond the critical value where the PC penetration limits the broadband penetration.

Instrumental variables Although the cable market share is to some extend exogenous (due to the number of homes passed or unobservable cost differences to the DSL technology), our estimates could suffer from an endogeneity problem if the broadband penetration and the market share of cable are simultaneously determined. To control for this we have performed an instrumental variable estimate, using the lagged variables of cable and cable 2 as instruments and additionally the market share of cable TV in the TV market as instruments (and its square). The latter variables are reasonable instruments since people who have broadband access via TV cable nearly always also use the TV cable for its original purpose, i.e. television. Since the cable TV networks were mainly rolled out in the 80s and 90s, the choice in the TV access market between cable, satellite or terrestrial clearly predates the decision on broadband access. Thus, it can be used as an instrument. Table 7, column 3 gives the regression results. The results are again very close to the pooled OLS presented in the main body of the paper. All signs and significance levels are preserved. The coefficients for cable and cable 2 are slightly higher. Using the slightly higher coefficients for cable and cable 2 would only slightly increase the positive welfare effect from additional consumer surplus. The critical assessment of the overall welfare effect 
would be left unaltered.

\begin{tabular}{|c|c|c|c|}
\hline & Pooled OLS & $\begin{array}{l}\text { Pooled OLS } \\
\text { with add. } \\
\text { variables }\end{array}$ & IV \\
\hline cable & $\begin{array}{l}0.241 \\
(7.80) * * *\end{array}$ & $\begin{array}{l}0.231 \\
(7.21) \star \star \star\end{array}$ & $\begin{array}{l}0.270 \\
(7.93) \star * *\end{array}$ \\
\hline cable2 & $\begin{array}{l}-0.235 \\
(7.56) * \star \star\end{array}$ & $\begin{array}{l}-0.228 \\
(7.55) * \star \star\end{array}$ & $\begin{array}{l}-0.277 \\
(7.60) * \star \star\end{array}$ \\
\hline retail & $\begin{array}{l}0.034 \\
(1.40)\end{array}$ & $\begin{array}{l}0.028 \\
(1.00)\end{array}$ & $\begin{array}{l}0.041 \\
(1.49)\end{array}$ \\
\hline inctv & $\begin{array}{l}0.055 \\
(5.48) \star \star \star\end{array}$ & $\begin{array}{l}0.057 \\
(4.33) \star \star \star\end{array}$ & $\begin{array}{l}0.060 \\
(5.71) * \star \star\end{array}$ \\
\hline isdn & $\begin{array}{l}-0.101 \\
(3.98) * * *\end{array}$ & $\begin{array}{l}-0.106 \\
(4.22) * \star *\end{array}$ & $\begin{array}{l}-0.107 \\
(4.03) \star \star \star\end{array}$ \\
\hline lngdp & $\begin{array}{l}0.048 \\
(2.75) * \star *\end{array}$ & $\begin{array}{l}0.054 \\
(1.57)\end{array}$ & $\begin{array}{l}0.046 \\
(2.45) \star \star\end{array}$ \\
\hline density & $\begin{array}{l}0.000 \\
(6.83) * \star \star\end{array}$ & $\begin{array}{l}0.000 \\
(5.96) * \star \star\end{array}$ & $\begin{array}{l}0.000 \\
(7.00) * \star *\end{array}$ \\
\hline Constant & $\begin{array}{l}-0.372 \\
(2.20) * \star\end{array}$ & $\begin{array}{l}-0.423 \\
(1.23) \\
\end{array}$ & $\begin{array}{l}-0.356 \\
(2.00) * \star\end{array}$ \\
\hline $\mathrm{pc}$ & NA & $\begin{array}{r}-0.020 \\
(0.35)\end{array}$ & $\mathrm{NA}$ \\
\hline passed & $\mathrm{NA}$ & $\begin{array}{l}0.012 \\
(0.77)\end{array}$ & $\mathrm{NA}$ \\
\hline R-squared & 0.72 & 0.72 & 0.71 \\
\hline
\end{tabular}

Robust $t$-statistics in parentheses

* significant at $10 \%$; $*$ significant at $5 \%$

$\star \star \star$ significant at $1 \%$

Table 7: Pooled OLS and alternative panel regressions

\subsubsection{Cross Country Analysis}

In order to investigate, to which extend the results are driven by the dynamics, i.e. the positive trend in pen, we look at some cross-country regressions. Table 8 shows the estimation results for the final period, 1Q2004. Although the results in isolation are not very instructive (we have 16 observations and 7 explanatory variables) it is reassuring that the signs of the coefficients are the same as in the panel estimation.

Regression with robust standard errors

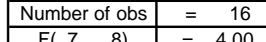

\begin{tabular}{|c|c|c|c|c|c|c|}
\hline pen & Coef. & Robust Std. Err. & $\mathrm{t}$ & $\mathrm{P}>\mathrm{t}$ & \multicolumn{2}{|c|}{$95 \%$ Conf. Interval } \\
\hline cable & 1.011351 & .4569909 & 2.21 & 0.058 & -.0424715 & 2.065174 \\
\hline cable2 & -1.594084 & .6484459 & -2.46 & 0.039 & -3.089403 & -.0987647 \\
\hline inctv & .0828188 & .0611909 & 1.35 & 0.213 & -.0582877 & .2239254 \\
\hline retail & .2297705 & .1344403 & 1.71 & 0.126 & -.0802494 & .5397903 \\
\hline isdn & -.0997707 & .2090355 & -0.48 & 0.646 & -.5818074 & .382266 \\
\hline Ingdp & .071854 & .1031128 & 0.70 & 0.506 & -.1659245 & .3096325 \\
\hline density & .0002855 & .0001366 & 2.09 & 0.070 & -.0000295 & .0006006 \\
\hline cons & -.8343984 & 1.050786 & -0.79 & 0.450 & -3.257515 & 1.588718 \\
\hline
\end{tabular}


Table 8: Estimation Results for 1Q2004

In addition we can perform cross country estimates for a larger set of countries. We have not used this larger set of countries in the main body of the paper as institutional differences are very large and information on the market details is not easily available (like retail market share, stakes of telecommunication incumbents in cable TV companies, and, in particular, investment data for cable companies and broadband prices).

Data are available from the research firm, Baskerville, only for a somewhat arbitrary set of 34 countries and for the third quarter of 2003. And, consistent information on some of the explanatory variables are not available even for this subset of countries. However, Table 9 shows estimation results for the sample of 34 countries with the explanatory variables cable, cable 2 , $\ln g d p$, and density. The sample comprises the 16 Western European Countries of the main body of the paper, plus USA and Canada, three Eastern European countries (Czech Republic, Poland, Hungary), and 13 countries from Acia/Pacific (South Korea, Hong Kong, Taiwan, Singapore, Japan, Australia, New Zealand, China, Malaysia, Philippines, India, Thailand, Indonesia, in decreasing order of broadband penetration). The results of this cross country analysis, however, support again the qualitative results of the main body of the paper: an inverted U-shaped relationship (with a peak at $\sim 40 \%$ market share of cable), a positive correlation with the gdp/capita and the population density. (GDP/Capita in current 2003 prices in USD, source: Worldbank, http://devdata.worldbank.org/d ata-query, population density on the basis of 1999 population, source:CIA World Factbook, http://www.photius.com/ wfb1999/ rankings/ population_density_1.html).

Regression with robust standard errors

\begin{tabular}{|c|c|}
\hline Number of obs & $=34$ \\
\hline $\mathrm{F}(4,29)$ & $=19.00$ \\
\hline Prob $>\mathrm{F}$ & $=0.0000$ \\
\hline R-squared & $=0.4084$ \\
\hline Root MSE & $=.1434$ \\
\hline
\end{tabular}

\begin{tabular}{|c|c|c|c|c|c|c|}
\hline pen & Coef. & Robust Std. Err. & $\mathrm{t}$ & $\mathrm{P}>\mathrm{t}$ & \multicolumn{2}{|c|}{$95 \%$ Conf. Interval } \\
\hline cable & .731301 & .4263582 & 1.72 & 0.097 & -.1406995 & 1.603301 \\
\hline cable2 & -.9167432 & .5612938 & -1.63 & 0.113 & -2.064718 & .2312315 \\
\hline Ingdp & .0339979 & .0150966 & 2.25 & 0.032 & .003122 & .0648739 \\
\hline density & .0000463 & .0000113 & 4.10 & 0.000 & .0000232 & .0000694 \\
\hline cons & -.2763884 & .1268264 & -2.18 & 0.038 & -.5357776 & -.0169992 \\
\hline
\end{tabular}

Table 9: Cross Country Estimates with 34 Countries

\section{References}

Aron, D., and D. Burnstein (2003): "Broadband Adoption in the United States: An Empirical Analysis," http://ssrn.com.abstract=386100.

BMWA (2003): "Information Society Germany 2006 (March 2003)," http://www.bmwi.de.

Börsenzeitung (2004): "Telekom Italia Erwartet Breitband Boom (Telecom Italia Expects Boom in Broadband)," 17/06/2004. 
Bourreau, M., And P. Dogan (2004): "Service-Based versus Facility Based Competition in Local Loop Access Networks," Information Economics and Policy, 16, 287-306.

(2005): "Unbundling the Local Loop," European Economic Review, 49(1), 173-199.

Chinn, M. D., and R. W. Fairlie (2004): "The Determinants of the Global Digital Divide: A Cross-Country Analysis of Computer and Internet Penetration," NBER Working Paper 10686.

Crandall, R. W. (2003): "Broadband Communications," Preliminary draft of a chapter for: Martin E. Cave, Sumit K. Majumdar and Ingo Vogelsang (eds.), the Handbook of Telecommunications, Vol. 2, North-Holland, forthcoming.

Distaso, W., P. Lupi, and F. M. Manenti (2004): "Platform Competition and Broadband Uptake: Theory and Empirical Evidence Form the European Union," http://ssrn.com/abstract=518382.

ERG (European Regulators Group) (2004): "Bitstream Access. ERG Common Position - Adopted at 2. April 2004," (03) 33rev1.

EU Commission (2002): "eEurope 2005: An Information Society for All. An Action Plan to Be Presented in View of the Sevilla European Counsil," COM 263 Final.

(2003a): "Commission Recommendation of 11 February 2003 on Relevant Product and Service Markets Within the Electronic Communications Sector Susceptible to Ex Ante Regulation in Accordance with Directive (2002/21/EC) of the European Parliament and of the Council on a Common Regulatory Framework for Electronic Communication Networks and Services (2003/311/EC)," Official Journal of the European Union L114/45 (8.5.2003).

(2003b): "Electronic Communications: The Road to the Knowledge Economy," COM (2003) 65 Final.

(2004): "eEurope Advisory Group. Connecting Europe at High Speed: National Broadband Strategies, Annexes," COM (2004)369 Final.

(2004b): "eEurope Advisory Group. Connecting Europe at High Speed: National Broadband Strategies," COM (2004)369 Final.

(2005): "Broadband Access in the EU: Situation at 1 January 2005," COCOM05-12 Final (1.6.2005).

EU Council (2002): "Presidency Conclusions, Barcelona European Council 15 and 16 March 2002," SN 100/1/02 REV.

Faulhaber, G. R., and C. Hogendorn (2000): "The Market Structure of Broadband Telecommunications," Journal of Industrial Economics, pp. 305329. 
Foros, O. (2004): "Strategic Investments with Spillovers, Vertical Integration and Foreclosure in the Broadband Access Market," International Journal of Industrial Organization, pp. 1-24.

Foros, O., And H. J. Kind (2003): "The Broadband Access Market: Competition, Uniform Pricing and Geographical Coverage," Journal of Regulatory Economics, pp. 215-235.

Goolsbee, A., And A. Petrin (2004): "The Consumer Gains from Direct Broadcast Satellites and the Competition with Cable TV," Econometrica, $72(2), 351-381$.

Hausman, J. A. (1997): "Valuing the Effect of Regulation in New Services in Telecommunications," Brookings Papers: Microeconomics, pp. 1-38.

Höffler, F. (2005): "Costs and Benefits from Infrastructure Competition. Estimating Welfare Effects from Broadband Access Competition," Preprints of the Max Planck Institute for Research on Collective Goods 1/2005, (1), http://www.coll.mpg.de.

Laffont, J.-J., And J. Tirole (2000): Competition in Telecommunications. MIT Press, Cambridge MA.

Liebowitz, S., and S. Margolis (1994): "Network Externalities: An Uncommon Tragedy," Journal of Economic Perspectives, 8, 133-150.

(2002): "Network Effects," edited by Martin Cave, Sumit Majumdar and Ingo Vogelsang, 75-96, Amsterdam, North-Holland.

Limkanen, E. (2002): "The eEurope Strategy.," Speech at the ETNO Conference "Making Broadband Happen in Europe", Brussels 3 December.

Mankiw, G. N., and M. D. Whinston (1986): "Free Entry and Social Inefficiency," RAND Journal of Economics, 17(1), 48-58.

OECD (2004a): "Benchmarking Broadband Prices in the OECD," DSTI/ICCP/TSIP(2003)8/final.

(2004b): "OECD Urges Governments to Increase Competition to Drive Broadband Growth," press release 25/05/2004.

Oftel (2003): “Annual Report," www.ofcom.org.uk.

Ovum (2003): "Cable: The Broadband Challenge," November 2003.

Perry, M. K. (1984): "Scale Economies, Imperfect Competition, and Public Policy," Journal of Industrial Economics, 32, 313-333.

Petrin, A. (2002): "Quantifying the Benefits of New Products: The Case of the Minivan," Journal of Political Economy, 110(4), 705-729. 